NASA Technical Memorandum 102491

\title{
Recent Advances in Nondestructive Evaluation Made Possible by Novel Uses of Video Systems
}

Edward R. Generazio and Don J. Roth Lewis Research Center

Cleveland, Ohio

Prepared for

MiCon 90: Advances in Video Technology: Materials sponsored by the American Society for Testing and Materials San Francisco, California, May 23-25, 1990 
RECENT ADVANCES IN NONDESTRUCTIVE EVALUATION MADE POSSIBLE BY NOVEL USES OF VIDEO SYSTEMS

Edward R. Generazio and Don J. Roth

REFERENCE: Generazio, E. R., Roth, D. J., "Recent Advances in Nondestructive Evaluation Made Possible by Novel Uses of Video Systems", MiCon 90: Advances in Video Technology for Microstructural Control, ASTM STP 1094, George Vander Voort, Ed., American Society for Testing and Materials, Philadelphia, 1990.

ABSTRACT: Complex materials are being developed for use in future advanced aerospace systems. High-temperature materials have been targeted as a major area of materials development. The development of composites consisting of ceramic or metallic matrix, and ceramic fibers or whiskers is currently being aggressively pursued internationally. These advanced materials are difficult and costly to produce; however, their low density and high operating temperature range are needed for the next generation of advanced aerospace systems. These new materials represent a challenge to the nondestructive evaluation community.

Video imaging techniques not only enhance the nondestructive evaluation, but they are also required for proper evaluation of these advanced materials. Specific research examples are given, highlighting the impact that video systems have had on the nondestructive evaluation of ceramics. An image processing technique for computerized determination of grain and pore size distribution functions from microstructural images is discussed. The uses of video and computer systems for displaying, evaluating, and interpreting ultrasonic image data are presented.

KEYWORDS: nondestructive evaluation, image processing, nondestructive testing, ceramics, silicon nitride, silicon carbide, ultrasonic, microstructure, grain size, porosity

Edward R. Generazio and Don J. Roth are Research Scientists at NASA Lewis Research Center, Cleveland, Ohio 44135. 


\section{INTRODUCTION}

Advanced high-temperature materials [1] are being developed for use in the next generation of aerospace systems. Recently, considerable attention has been given to monolithic $\mathrm{SiC}$ and $\mathrm{Si}_{3} \mathrm{~N}_{4}$ ceramic materials [2] for these high-temperature applications. Research on monolithic ceramics subsequently led to the current developmental research on advanced high-temperature composites. These composites consist of particles, whiskers, or fibers in metal or ceramic matrices. A variety of processing techniques are being investigated in an effort to produce high-temperature composites with optimized thermal and mechanical properties. Plasma spraying, reaction bonding, slurry pressing, and sintering are typical techniques used to produce high-temperature ceramics. These processes often result in a material that has a widely variable microstructure. Typical microstructural variations, such as porosity, agglomerates, grain size, interfacial structure between phases, and orientation of phases and grains, all play a role in determining the material's properties. The importance and effects of these microstructural variations on the composite material's thermal and mechanical properties are being aggressively researched [1-8].

It is generally accepted that neither conventional x-ray radiographic nor ultrasonic evaluation is able to identify, a priori, defects that will eventually cause failure in ceramics. There are two problems that prevent us from obtaining this crucial information a priori. The first is that these ceramic materials, even the monoIithic ones, are complex systems that yield $x$-ray and ultrasonic data that are difficult to interpret. For example, we found that standard techniques for making ultrasonic attenuation measurements for metals (i.e., single point measurements) were inadequate for monolithic ceramics $[9,10]$; therefore, imaging techniques are required. We must reevaluate and modify our NDE methods and theories and adapt them to these new systems. The second problem is that the complicated structure of monolithic and composite ceramics has caused the modification of NDE methods and theories to be slow and the interpretation of ultrasonic and radiographic data to remain ambiguous.

In spite of these problems, NDE technologies can be expected to nonintrusively monitor and track processes that lead to the creation of critically sized pores and the matrix-second phase interface in composites. In order to assist in the development of these advanced ceramic materials, NDE must reposition itself with respect to the materials' development; that is, NDE must be performed during the material's processing rather than after the ceramic material has been produced. Perhaps NDE will have to be incorporated in situ and at the end of each processing stage. In situ NDE during developmental processing of ceramic materials is a new concept that can be carried over to total quality management during manufacturing.

Imaging by video and computer systems has proven crucial to promoting NDE technology to the level where it can have an impact on the development of advanced high-temperature materials. These systems have been instrumental in guiding and expanding NDE technologies toward the in situ processing environment. The work presented herein gives an overview of two new image-intensive techniques developed specifically 
for assisting in producing these advanced materials: tone-pulse encoding of microstructural images, to determine microstructure size distributions; and precision acoustic imaging of porosity variations produced during sintering.

\section{MICROSTRUCTURE SIZE DISTRIBUTIONS}

Material characteristics, such as tensile strength, hardness, yield stress, fracture stress, impact resistance, and fracture toughness, are directly related to grain, porosity, and whisker size distributions. Thus, prediction of these properties requires detailed knowledge of the related size distributions. The theoretical determination of size distributions has received considerable attention [11]. Several accepted techniques determine the mean grain or pore size without measuring the size distribution function. These techniques, however, are not applicable to any arbitrary system; the researcher must often determine which method will yield the most accurate data. The guidelines for making this decision are quite general and, as such, can lead to considerable error in the results [11].

In this section, an objective technique is described for determining the grain and pore size distribution functions from a metallographically prepared sample. The resulting relationship is two-dimensional and yields the grain and pore size distribution functions from which the mean shape, size, and orientation can be obtained.

The theory for the tone-pulse-encoding technique can be found elsewhere [12]. Briefly, a microstructural image (Fig. 1) is digitally recorded into a 512 by 512 pixel array by a video camera attached to a computer-controlled video digitizer. This image may reveal grain and pore boundaries. The preferred, but not required, method is to work with images that reveal only one feature such as grains or, perhaps, pores.

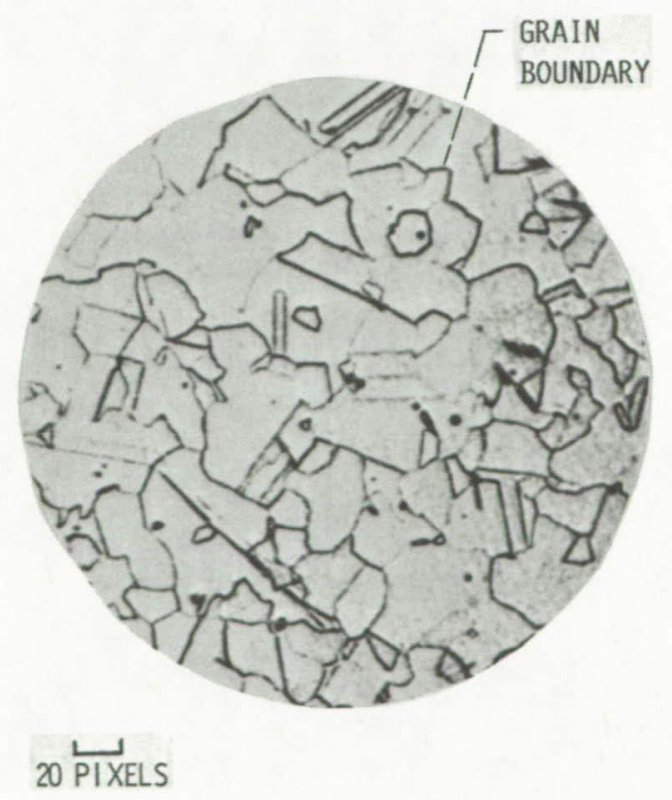

Fig. 1 -- Digitized image of grain structure. 
A two-dimensional gradient of the image (Fig. 2) is used to enhance the boundaries of the feature that we are interested in. The optical noise in the gradient image is removed by using a two-level gray scale to highlight the boundaries. Next, a tone-pulse-encoded image containing the fundamental harmonics of each grain is generated. The tone pulse begins and ends at a grain boundary and has a width equal to the width of the grain. The amplitude of the tone pulse is inversely proportional to the width. A new tone pulse is started at an adjacent grain boundary, which generally has a different width. This is done digitally, starting from the center of the image and proceeding outward along the radius to the perimeter of the image. The process is repeated for all angles ( 0 to $2 \pi \mathrm{rad}$ ) so that a frequency-encoded image appears as shown in Fig. 3.

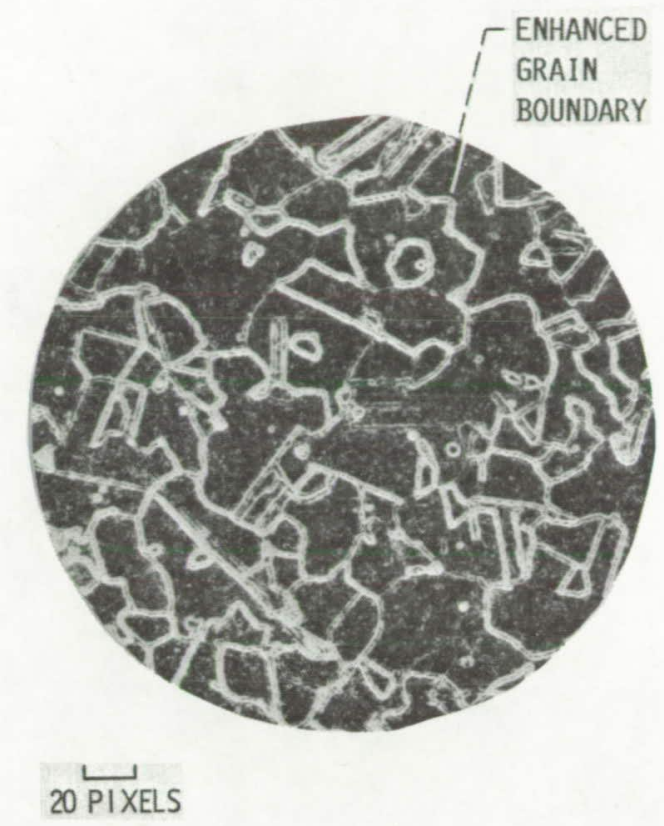

Fig. 2 -- Two-dimensional gradient of Fig. 1 exhibits enhanced grain boundaries.

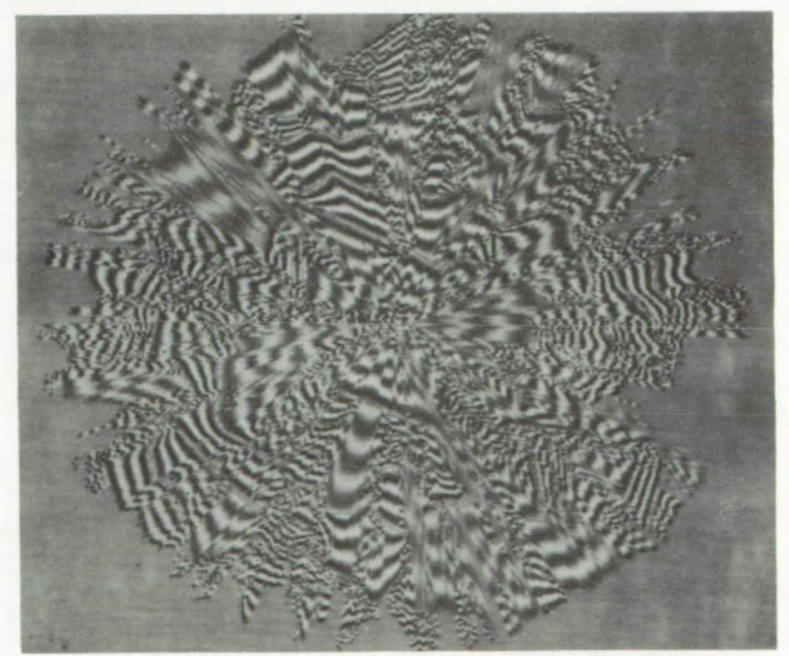

Fig. 3 -- Tone-pulse-encoded image. 


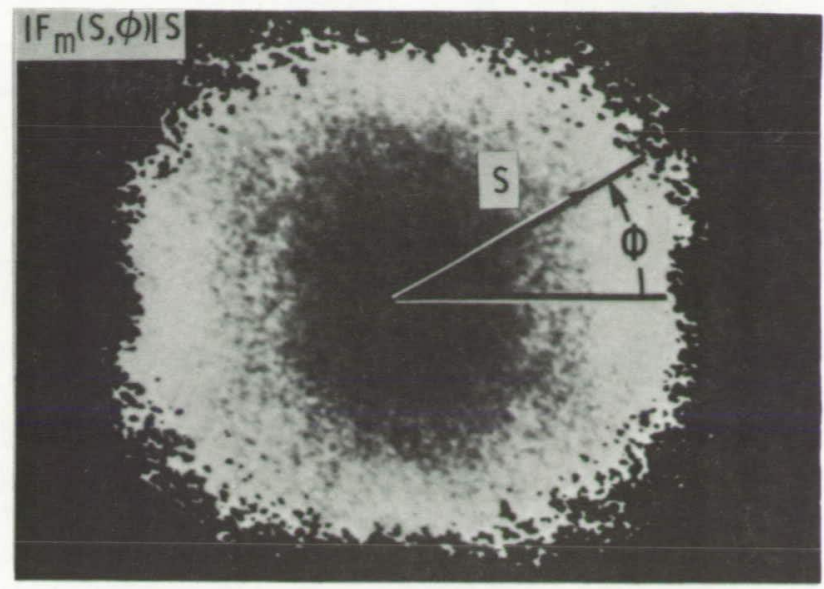

Fig. 4 -- Density of length components as a function of reciprocal vector $s$.

The density of length components $\left|F_{m}(s, \phi)\right| s$ ( $F i g .4$ ) is obtained by multiplying the two-dimensional Fourier transform, $\left|F_{m}(s, \phi)\right|$ of the tone-pulse-encoded image by the magnitude $s$ of the radial vector. Here $\phi$ is the polar angle and $s$ is the reciprocal vector of the spatial vector $r^{\prime}$. By replacing $s$ with $1 / r^{\prime}$ in $\left|F_{m}(s, \phi)\right| s$, we obtain the density of length components $P\left(r^{\prime}, \phi\right)$ as a function of length $r^{\prime}$ as shown in Fig. 5. The mean grain length $D(\phi)$ along any direction is obtained from $P\left(r^{\prime}, \phi\right)$ and is given by

$$
D(\phi) \equiv \frac{\sum_{r^{\prime}}\left|P\left(r^{\prime}, \phi\right)\right| r^{\prime}}{\sum_{r^{\prime}}\left|P\left(r^{\prime}, \phi\right)\right|}
$$

Equation 1 yields the mean grain shape from which the orientation can be obtained.

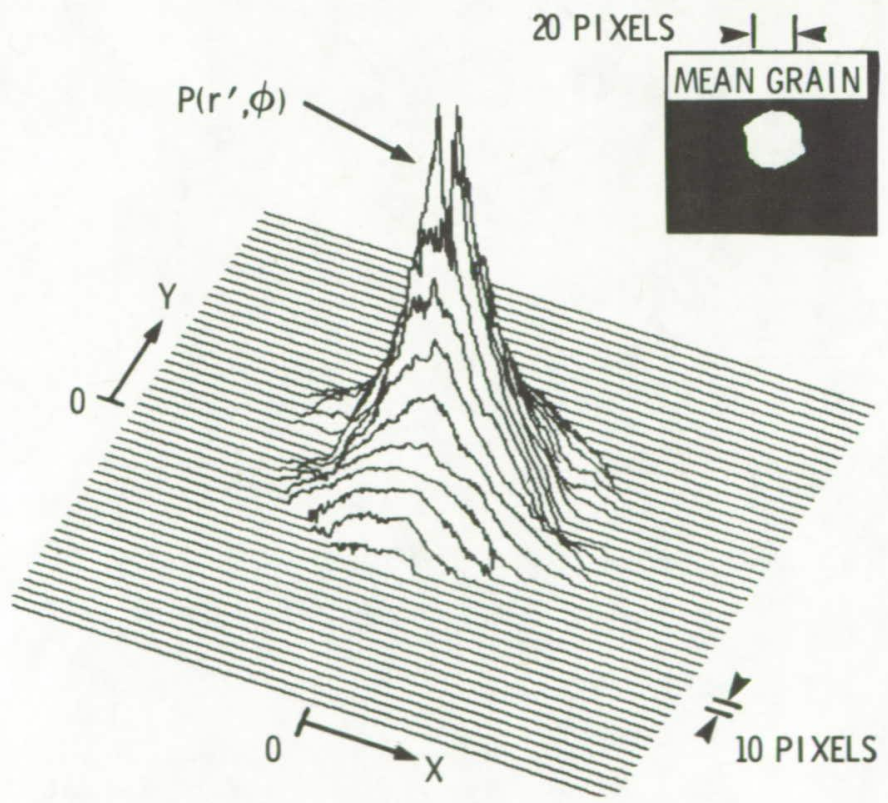

Fig. 5 -- Density of length components as a function of length. 
The tone-pulse-encoding technique can be modified for determining porosity (Fig. 6) size distributions. The area that is tone-pulse encoded between the pores is masked out so that only the pores are tone-pulse encoded. Subsequent processing yields the porosity size distribution function.

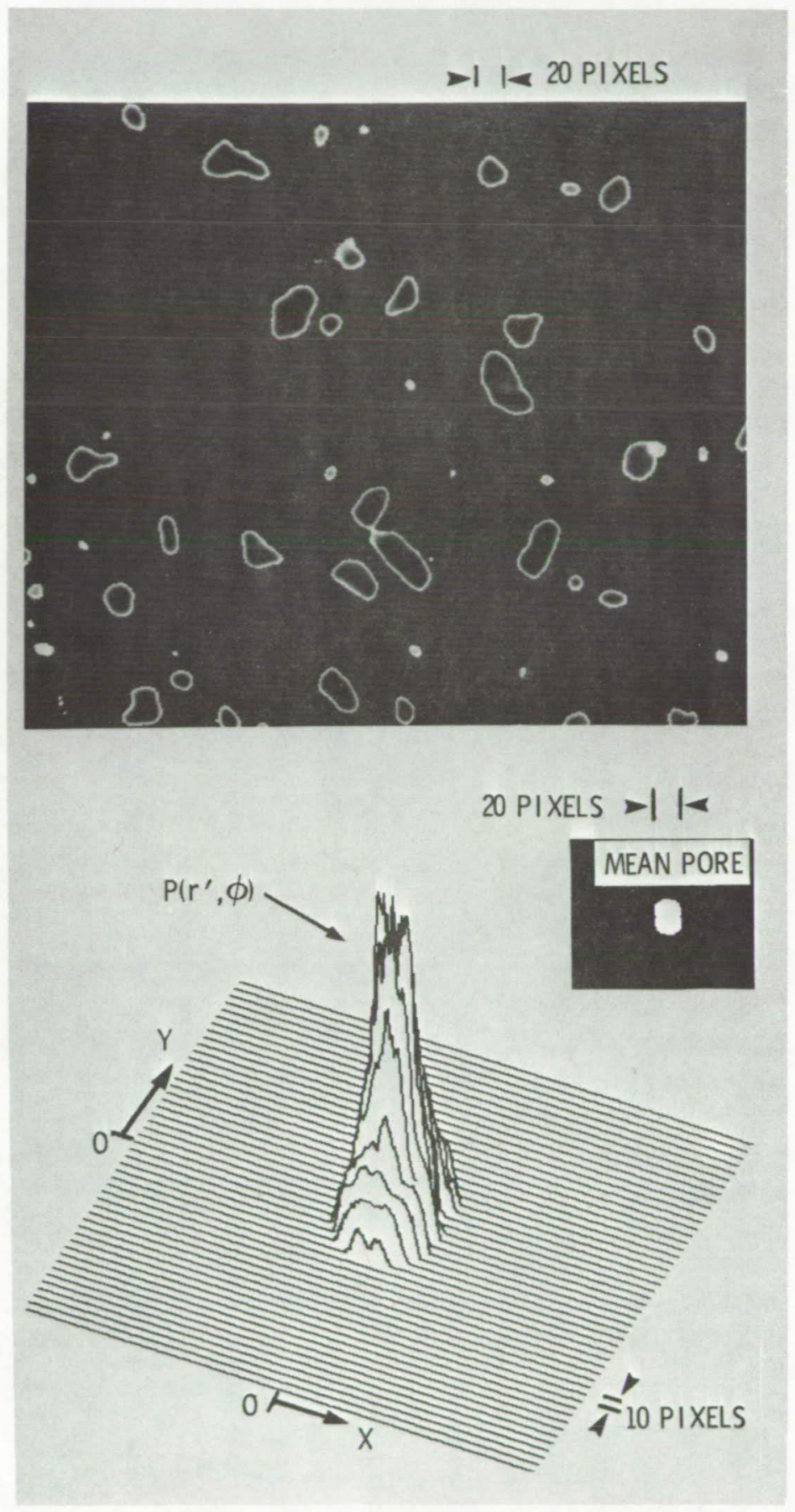

Fig. 6 -- Photomicrograph of pores, density of length components, and mean pore. Image of pores is enhanced by clipping data above a predetermined level to a constant value. 


\section{PRECISION ACOUSTIC IMAGING}

Ultrasonic imaging can be done by several techniques. The most common is that used by commercially available ultrasonic immersion C-scanning systems. An ultrasonic wave of known amplitude $A_{0}$ is transmitted through a sample as shown in Fig. 7. The final amplitude $A_{f}$ or C-scan image is a representation of relative attenuation or energy lost by the ultrasonic wave during its trip from the transmitter to receiver. Unfortunately, C-scan images are not representations of the energy lost by the ultrasonic wave solely because of the internal structure of the sample. The ultrasonic reflection coefficients at the water-to-sample interfaces, which are generally assumed to be constant, are actually large and varying. These reflection coefficients must be included in the analysis to determine the actual energy loss, or attenuation, due to the inner structure of the sample, and they must be used in determining the accuracy of the acoustic image as well as the accuracy of the imaging technique. For this reason, the equations for determining the uncertainty in the measurement of ultrasonic attenuation are highlighted in this work.

First consider the immersion scanning method. To obtain the reflection coefficient at the back surface, a modified two-transducer arrangement must be used (Fig. 8), where the transducers are both transmitters and receivers. The uncertainty $\sigma_{\alpha}$ in the attenuation measurement for this immersion arrangement is given by

$$
\begin{aligned}
\left(\frac{\sigma}{\alpha}\right)\left(\frac{S}{N}\right) & =\frac{1}{2 \alpha x}\left[\frac{\left(1-R_{b}^{2}\right)^{2}\left[\left(1+R_{f}^{2}\right)^{2}+4 R_{f}^{2}\right]}{\left(1-R_{f}^{2}\right)^{2}\left(1-R_{b}^{2}\right)^{2}}\right. \\
& \left.+\frac{\left(1-R_{f}^{2}\right)^{2}\left[\left(1+R_{b}^{2}\right)^{2}+4 R_{b}^{2}\right]}{\left(1-R_{f}^{2}\right)^{2}\left(1-R_{b}^{2}\right)^{2}}+\frac{2\left(1-R_{f}^{2}\right)\left(1-R_{b}^{2}\right) e^{2 \alpha x}}{\left(1-R_{f}^{2}\right)^{2}\left(1-R_{b}^{2}\right)^{2}}\right]^{1 / 2}
\end{aligned}
$$

where $S / N$ is the signal-to-noise ratio of the input ultrasonic pulse, $\alpha$ is the measured attenuation, and $R_{f}$ and $R_{b}$ are the reflection coefficient magnitudes on the front and back surfaces of the sample, respectively, and $x$ is the sample thickness.

An alternative technique to immersion scanning is contact scanning. The experimental arrangement for this technique, which uses a single transducer to make precise and accurate attenuation measurements, is shown in Fig. 9. An ultrasonic wave is introduced into the sample via the buffer rod-couplant-sample (BCS) interface. The ultrasonic wave subsequently echoes within the sample. By measuring both the reflection coefficient [13] $R_{f}$ at the BCS interface, and the appropriate echoes, the ultrasonic attenuation can be determined. The uncertainty in the attenuation measurement for this contact arrangement is given by 


$$
\left(\frac{\alpha}{\alpha}\right)\left(\frac{S}{N}\right)=\frac{1}{2 \alpha x}\left[\left\{\frac{\left[R_{b}^{4} R_{f}^{2}+e^{4 \alpha x}\right] e^{4 \alpha x}}{\left(1-R_{f}^{2}\right)^{2}}+R_{b}^{4}+R_{b}^{4} R_{f}^{2}\right\} \frac{1}{R_{b}^{4} R_{f}^{2}}+2\right]^{1 / 2}
$$

Note that the sample need not be air backed. That is, $\left|R_{b}\right|$ may be less than one.

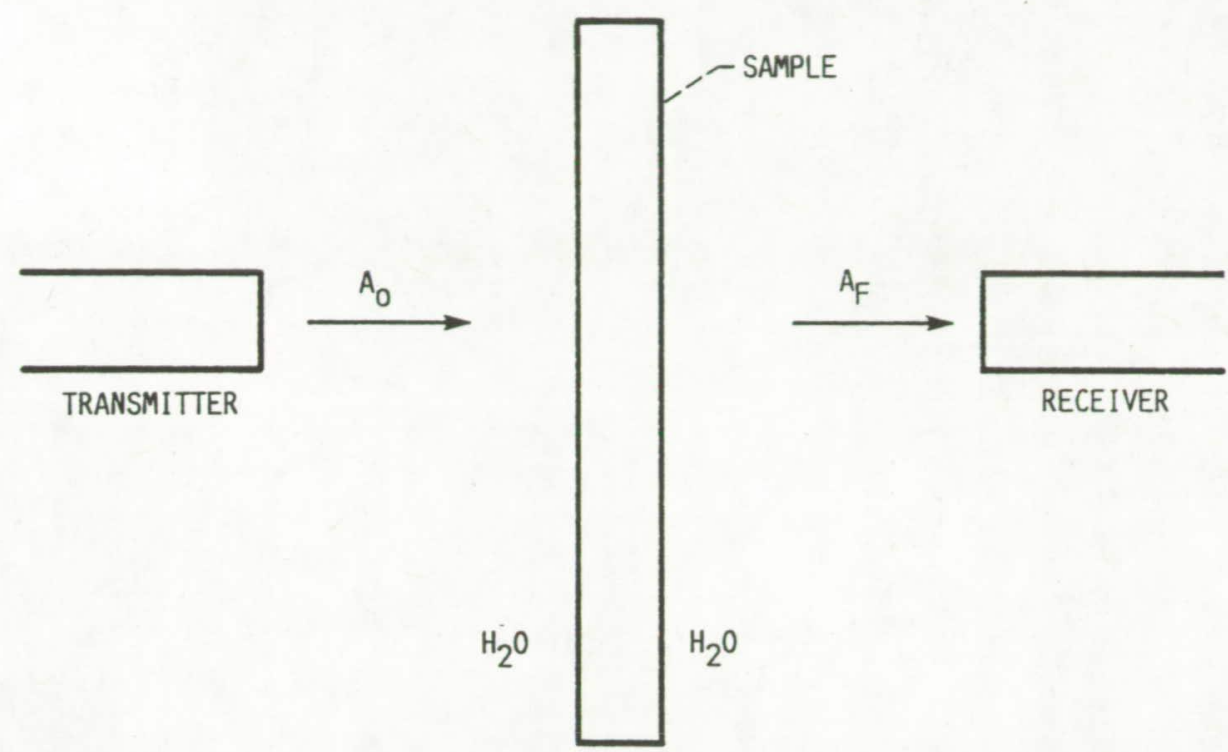

Fig. 7 -- Standard immersion ultrasonic C-scanning arrangement.

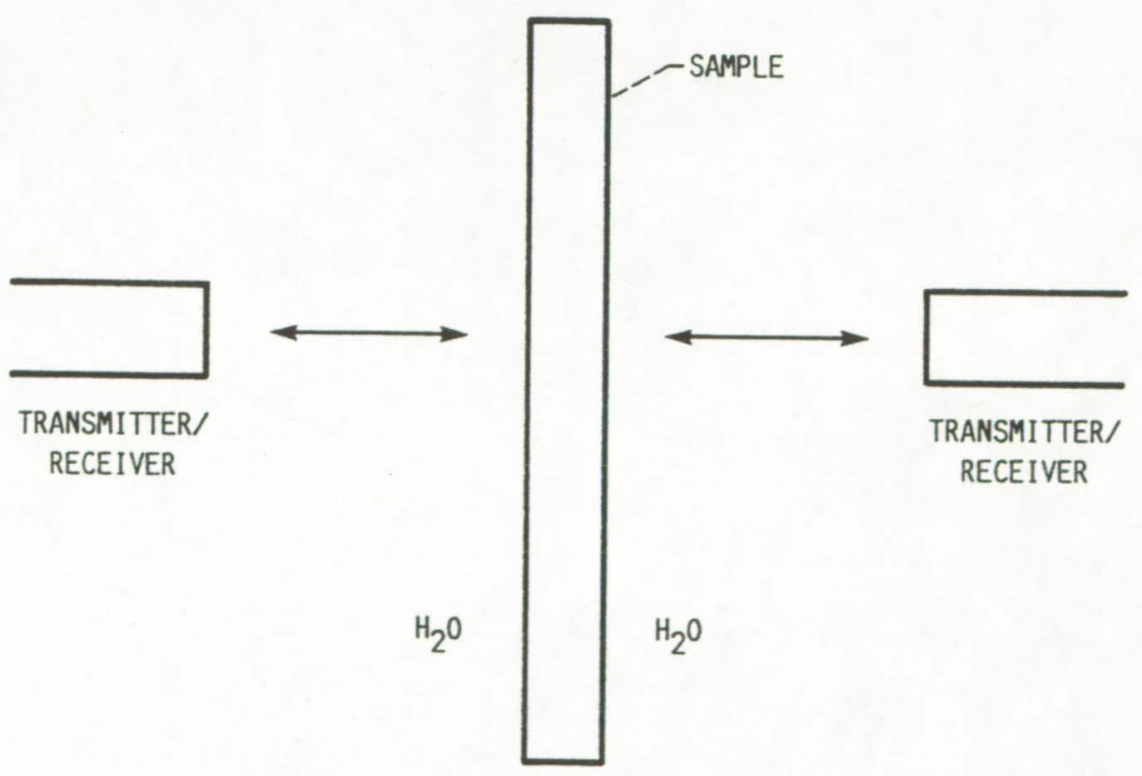

Fig. 8 -- Modified immersion ultrasonic scanning arrangement needed for determining reflection coefficients at front and back surfaces. 


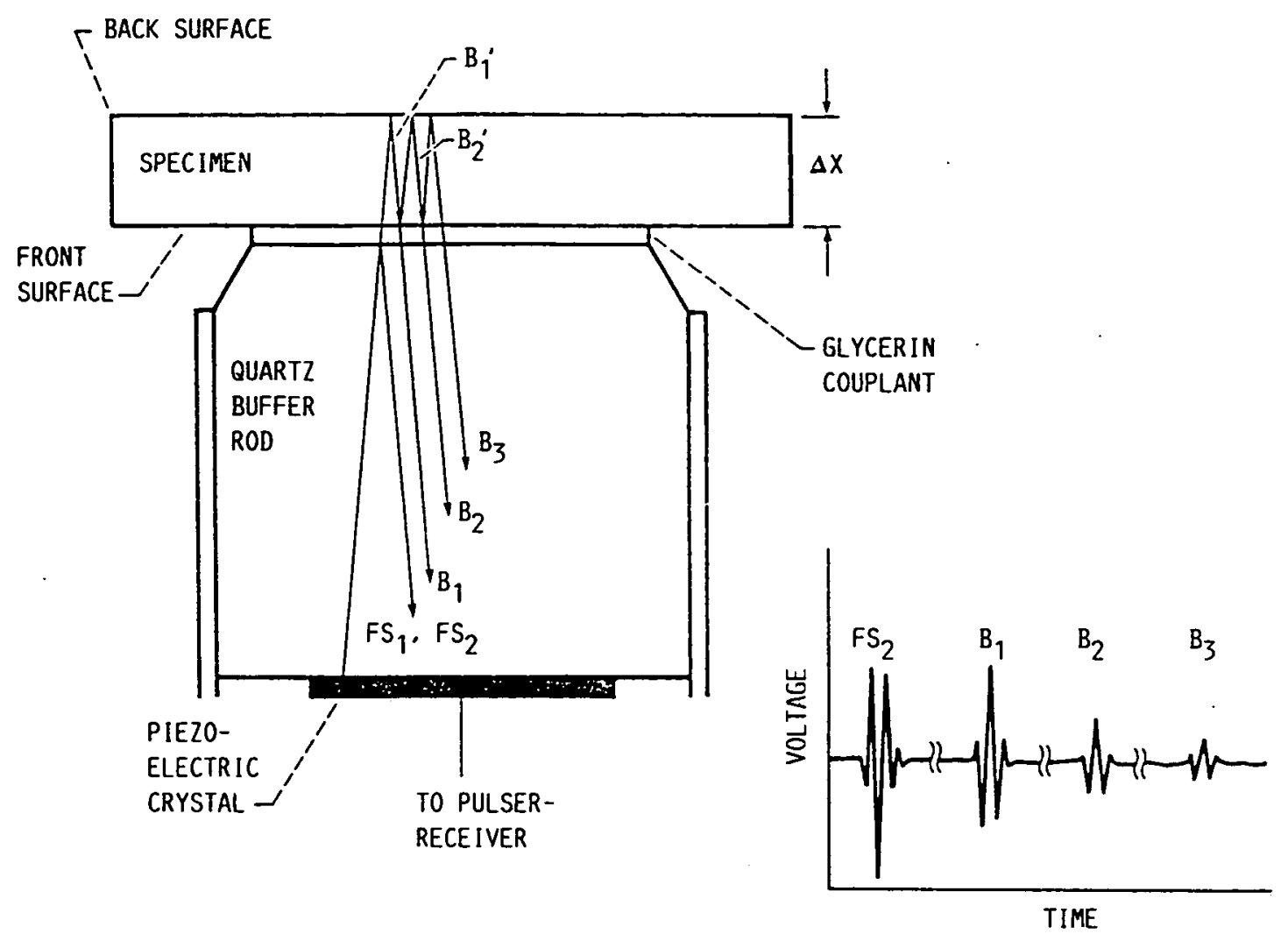

Fig. 9. - Configuration for contact ultrasonic measurements.

Equations 2 and 3 are shown graphically in Fig. 10. The experimental configuration having the lowest uncertainty values obtained from Eqs. (2) and (3) is shown. The solid line in the figure can be used to make a decision about which technique should be applied for a particular experimental sample. Above the solid line a precision contact pulse-echo measurement is preferred. Below the solid line an immersion through transmission yields the least uncertainty in the attenuation measurement.

Immersion ultrasonic systems generally have similar reflection coefficients for $R_{f}$ and $R_{b}$. The uncertainty is symmetric with respect to the $R_{f}=R_{b}$ axis for immersion measurements. The long-dashed line in Fig. 10 indicates the path used to determine the uncertainty. Many solid materials will fit on this curve between 0.84 and 0.97 .

Figure 11 shows the uncertainty for $\mathrm{Ni}, \mathrm{Pb}, \mathrm{Al}, \mathrm{PMMA}, \mathrm{PMC}, \mathrm{AlO} \mathrm{O}_{2}, \mathrm{~W}$, $\mathrm{Si}_{3} \mathrm{~N}_{4}$, and $\mathrm{SiC}$ for both immersion $\left(R_{f}=R_{b}\right.$ ) and contact ultrasonic methods. When evaluating $\mathrm{Ni}, \mathrm{SiC}, \mathrm{Si}_{3} \mathrm{~N}_{4}, \mathrm{AlO}_{2}$, and $\mathrm{W}$, the contact pulse-echo method yields the least uncertain and the most accurate attenuation measurement. For example, if we consider using the immersion scanning technique with a tungsten sample, the reflection coefficients are $R_{b}=R_{f}=0.97$, so we obtain $\sigma^{\prime}=4.52$. Here we assume that $2 \alpha x=1$ and $\alpha=1$ for comparison, and $\sigma^{\prime}=\log \left[\sigma_{\alpha} / \alpha(S / N)\right]$. The same sample in a contact scanning system will have $R_{f}=0.74$ and $R_{b}=1.0$, to yieid $\sigma^{\prime}=3.14$. Therefore, for tungsten, contact scanning will yield a more accurate result. 


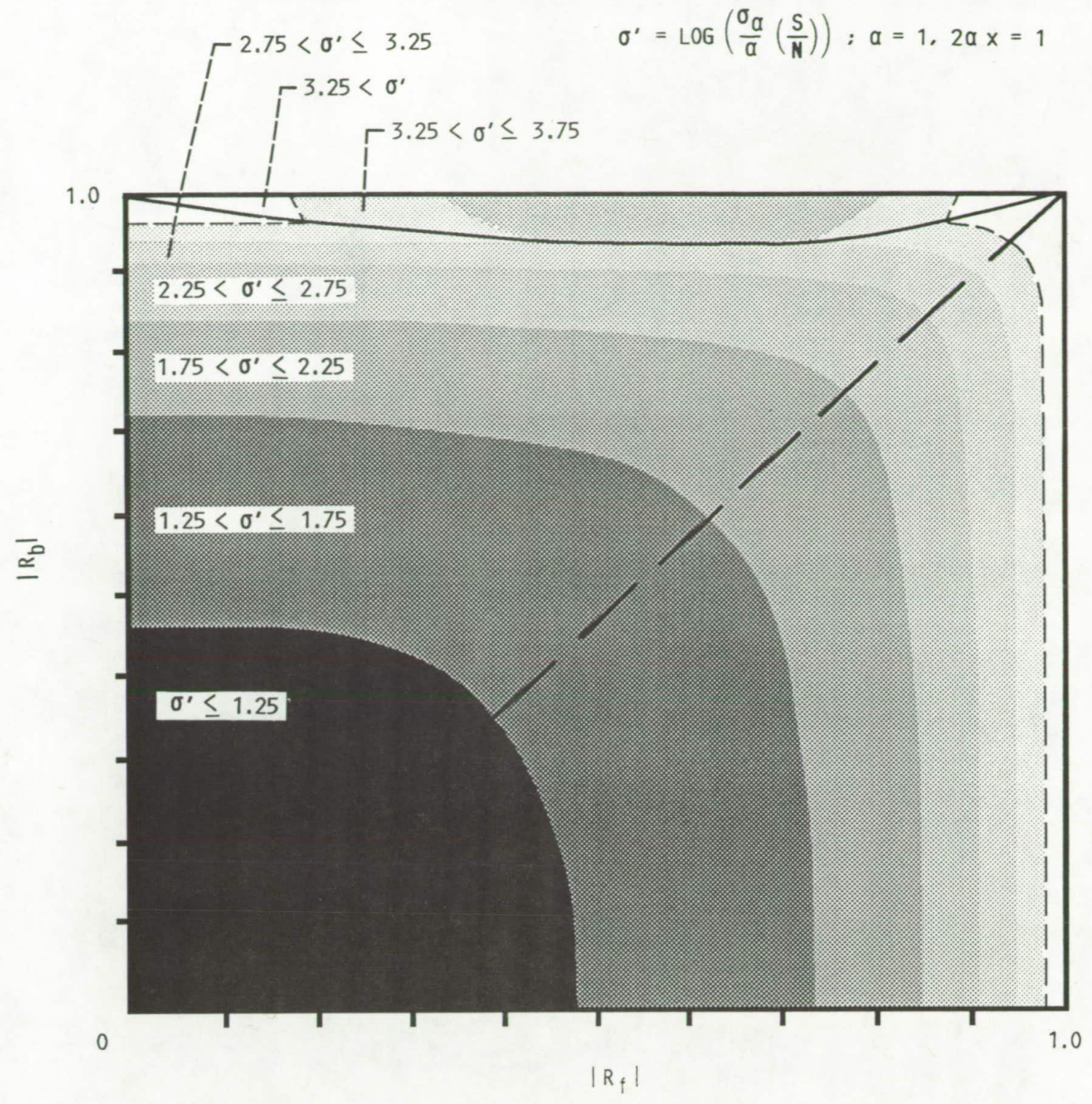

Fig. 10 -- Uncertainty in the attenuation as a function of front and back surface reflection coefficients for both immersion and contact ultrasonic scanning. Above the solid line the contact scanning method is more accurate. The long-dashed line indicates the uncertainty for the immersion arrangement where the sample has identical reflection coefficients on both sides. Here, $2 \alpha x=1, \alpha=1$, and $\sigma^{\prime}=\log \left[\sigma_{\alpha} / \alpha(S / N)\right]$.

A precision acoustic scanning system (PASS) is shown in Fig. 12 . A detailed description of the operation and use of the PASS is given elsewhere [9-10, 13-14]. Briefly, an ultrasonic wave transmitterreceiver (transducer) is scanned over the surface of the sample. After collection and subsequent Fourier analysis of the appropriate waveforms, an accurate determination of velocity and attenuation can be made. This is done at different positions on the sample, in an organized array. The resultant data yield velocity and attenuation maps that are displayed on a video system. 


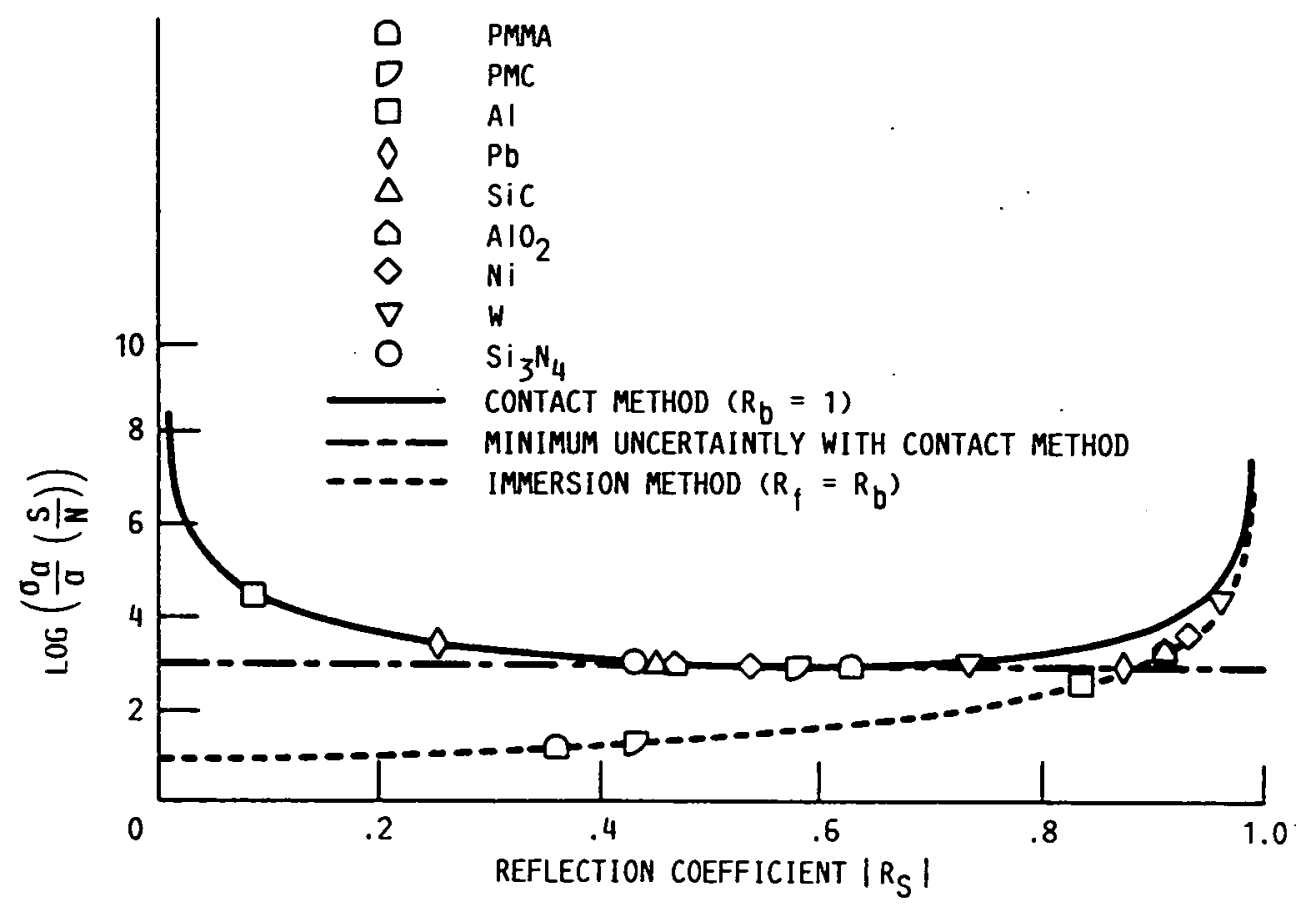

Fig. 11 -- Uncertainty comparison for several materials. For $\mathrm{AlO}_{2}, \mathrm{Ni}, \mathrm{W}, \mathrm{SiC}$, and $\mathrm{Si}_{3} \mathrm{~N}_{4}$, the uncertainty is lower with a contact scanning method. Curves are generated from Eqs. 2 and 3. Here, $2 \alpha x=1, \alpha=1$, and $\sigma^{\prime}=\log \left[\sigma_{\alpha} / \alpha(S / N)\right]$.

A typical data set, from which approximately 25 images can be obtained, will contain about 2000 waveforms, 2000 Fourier spectra, and 40000 attenuation and velocity values. The original acquired data uses about 20 Mbyte of computer memory storage, whereas the reduced data set containing the attenuation [13], velocity [10], and reflection coefficient [13] images occupies about 5 Mbyte.

Evaluating an image often requires examination of both the raw and reduced data for a particular point in the image. A data retrieval program provides the necessary interface to allow immediate retrieval of data, which are displayed in a video image overlay. For example, the data for one point (determined by the cursor location) in an ultrasonic image of velocity (Fig. 13) are displayed in an overlay as shown in Fig. 14. This display contains waveforms and their Fourier spectra, reflection and attenuation coefficients (which may be used to determine accuracy), phase velocity as a function of frequency, and group velocity (determined by cross correlation). We need to examine all of these data for irregularities when evaluating a particular point on the ultrasonic image. For example, if a quantitative measure of the difference in density between two points is needed, it can be determined from the group velocity at these points on the appropriate overlays. Also, the frequency dependence that attenuation exhibits has been related to the subsurface pore or flaw sizes [15], the state of the recrystallization in metals [16], and the mean grain size [17]. Easy access to this type of information is made possible by the use of a video system. 

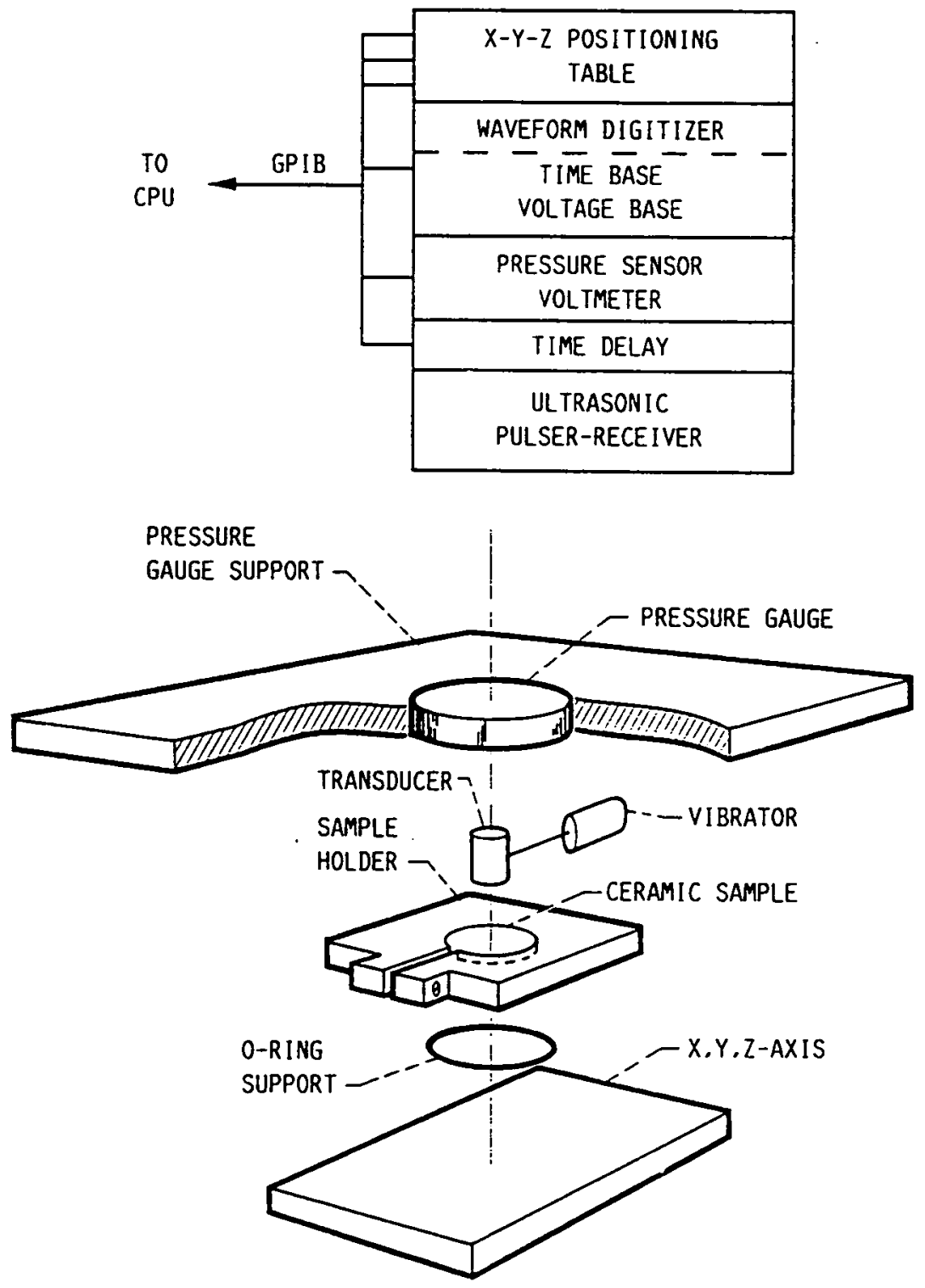

Fig. 12. - Precision acoustic scanning system (PASS). 


\section{ORIGINAL PAGE \\ COLOR PHOTOGRAPH}

VELOCITY,

CM/ $/ \mathrm{SEC}$

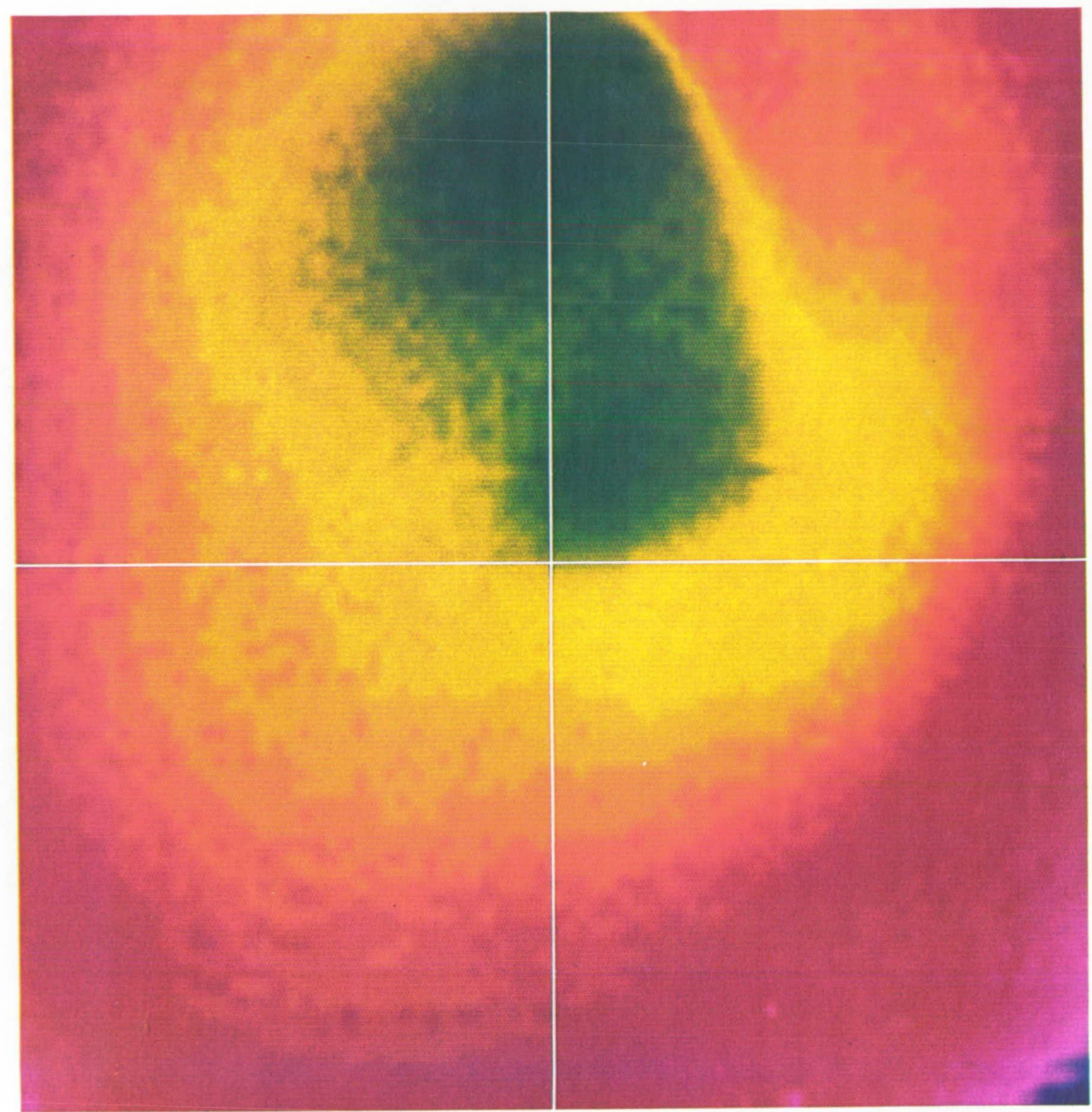

$-1.15$

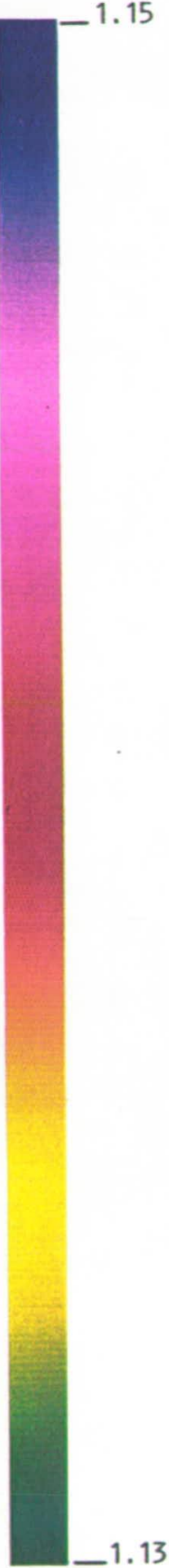

Fig. 13 -- Ultrasonic image of SiC produced by the PASS. Cursor indicates the physical point on the sample that needs to be evaluated. Area shown is $2 \mathrm{~cm} \times 2 \mathrm{~cm}$. 


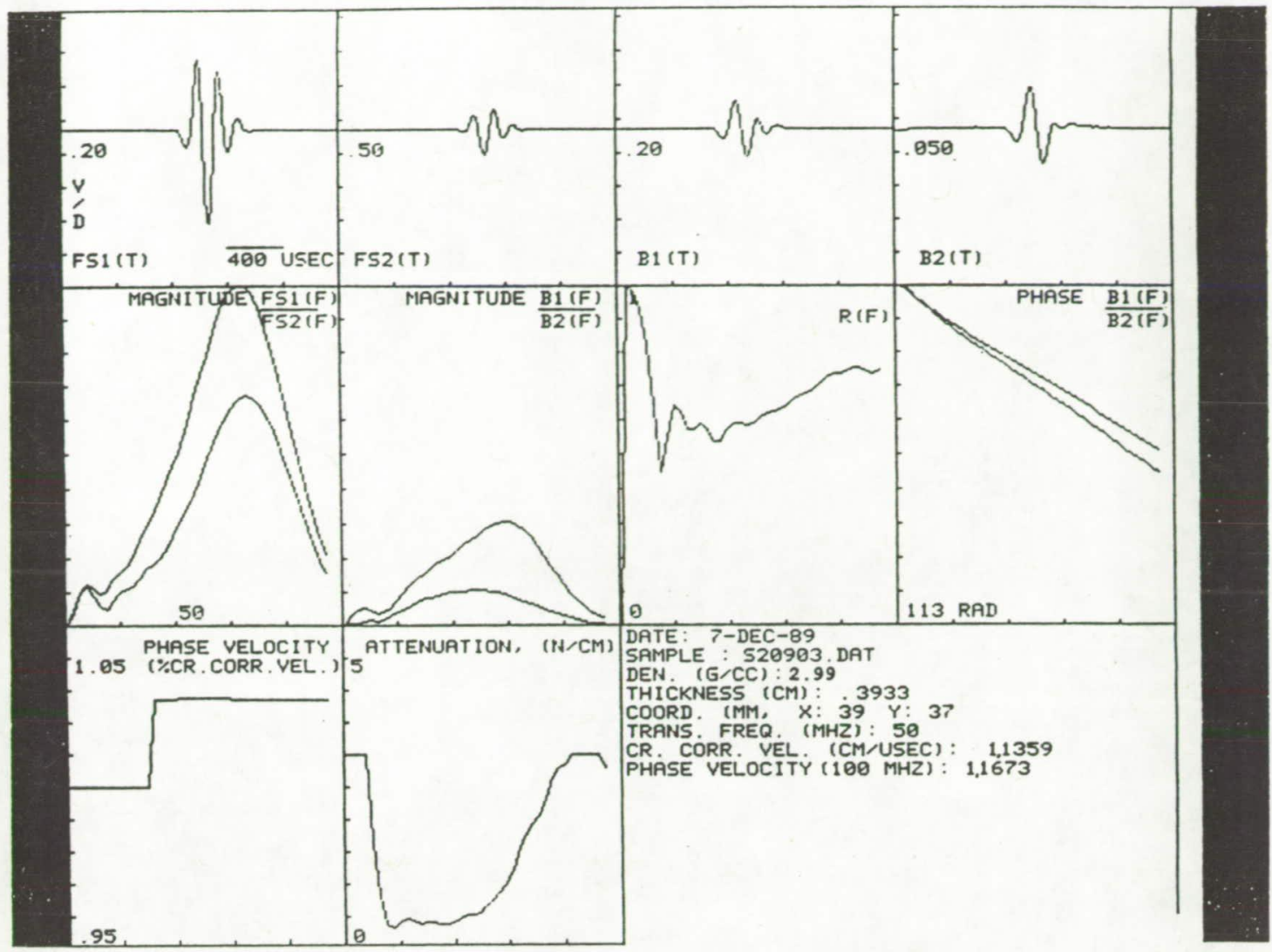

Fig. 14 -- Pop-up screen revealing data that are obtained for cursor position shown in Fig. 13. This screen contains all required data and analysis for proper evaluation of the ceramic at this cursor position.

Video and computer systems have also played a crucial role in the interpretation of ultrasonic data. In the past, only a few measurements would have been taken at a small number of positions in order to ultrasonically, nondestructively evaluate a material. The data obtained from these measurements would have been averaged, and the standard deviation determined. These two values, the average and the standard deviation, would then be used to classify the sample. However, these two values may not be sufficient for giving a full understanding of the internal structure of the material. For example, from nine measurements we can calculate the average ultrasonic attenuation and its standard deviation at $100 \mathrm{MHz}$ in a ceramic sample as 1.1 and $0.3 \mathrm{~Np} / \mathrm{cm}$, respectively. But this information does not describe the cloudlike attenuation structure [10] revealed in the pass-obtained video image of that sample (Fig. 15). Another example of video imaging's impact on the interpretation of ultrasonic data is shown in Figs. 16 and 17 . Previously, ultrasonic attenuation in ceramics was believed to be due to diffractive scattering from individual grain and pore boundaries; therefore, an increase in the number or size of pores yielded an increase in the attenuation. These figures dramatically show that the high ultrasonic attenuation observed is due to diffractive scattering at regions exhibiting large velocity (density) gradients [9], not increased porosity. 


\section{ORIGINAL PAGE \\ COLOR PHOTOGRAPH}

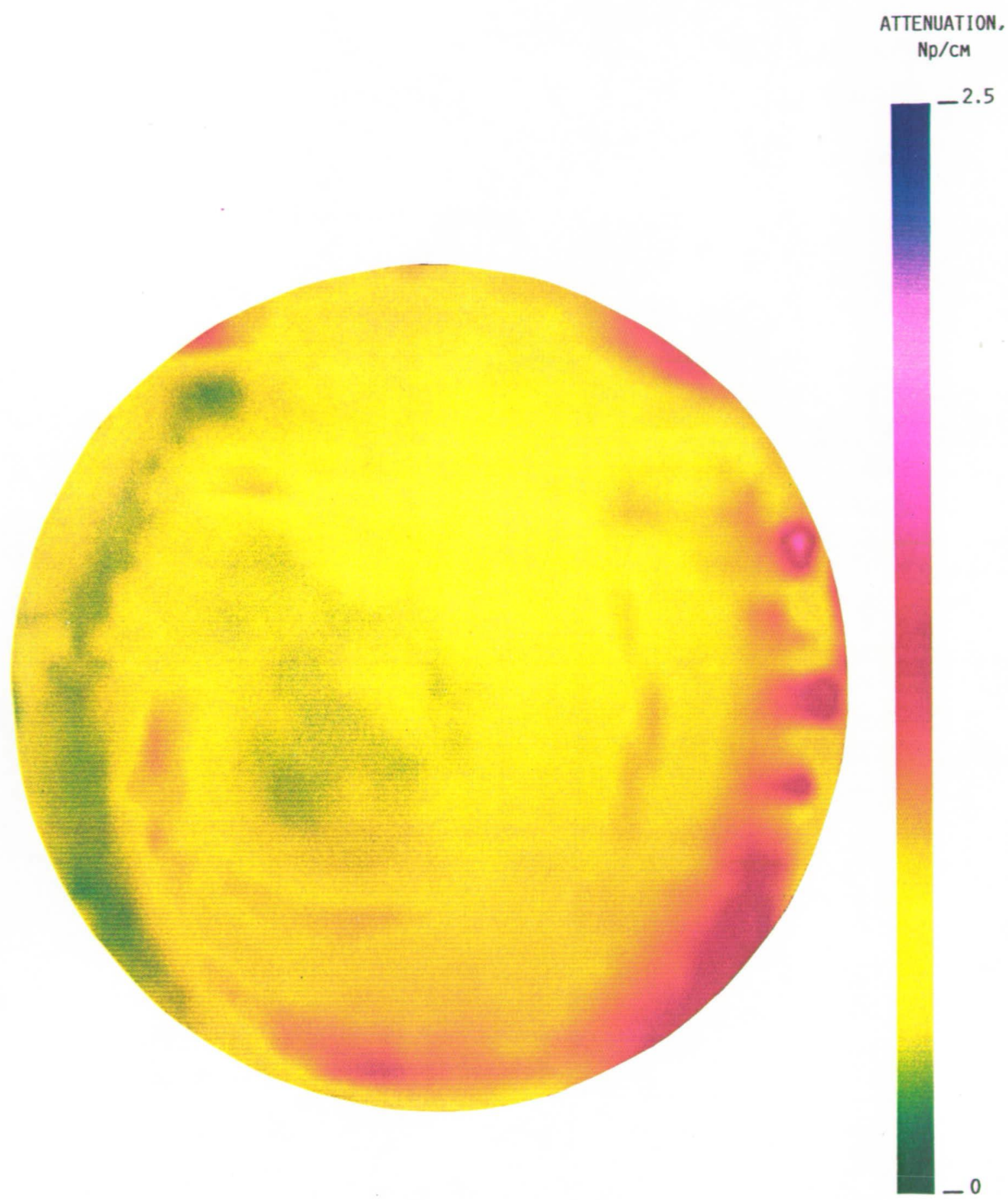

Fig. 15 -- Pass-produced ultrasonic attenuation image of SiC. Video image reveals the cloudlike porosity structure within the sample. Disk has a diameter of $4 \mathrm{~cm}$. 


\section{ORIGINAL PAGE \\ COLOR PHOTOGRAPH}

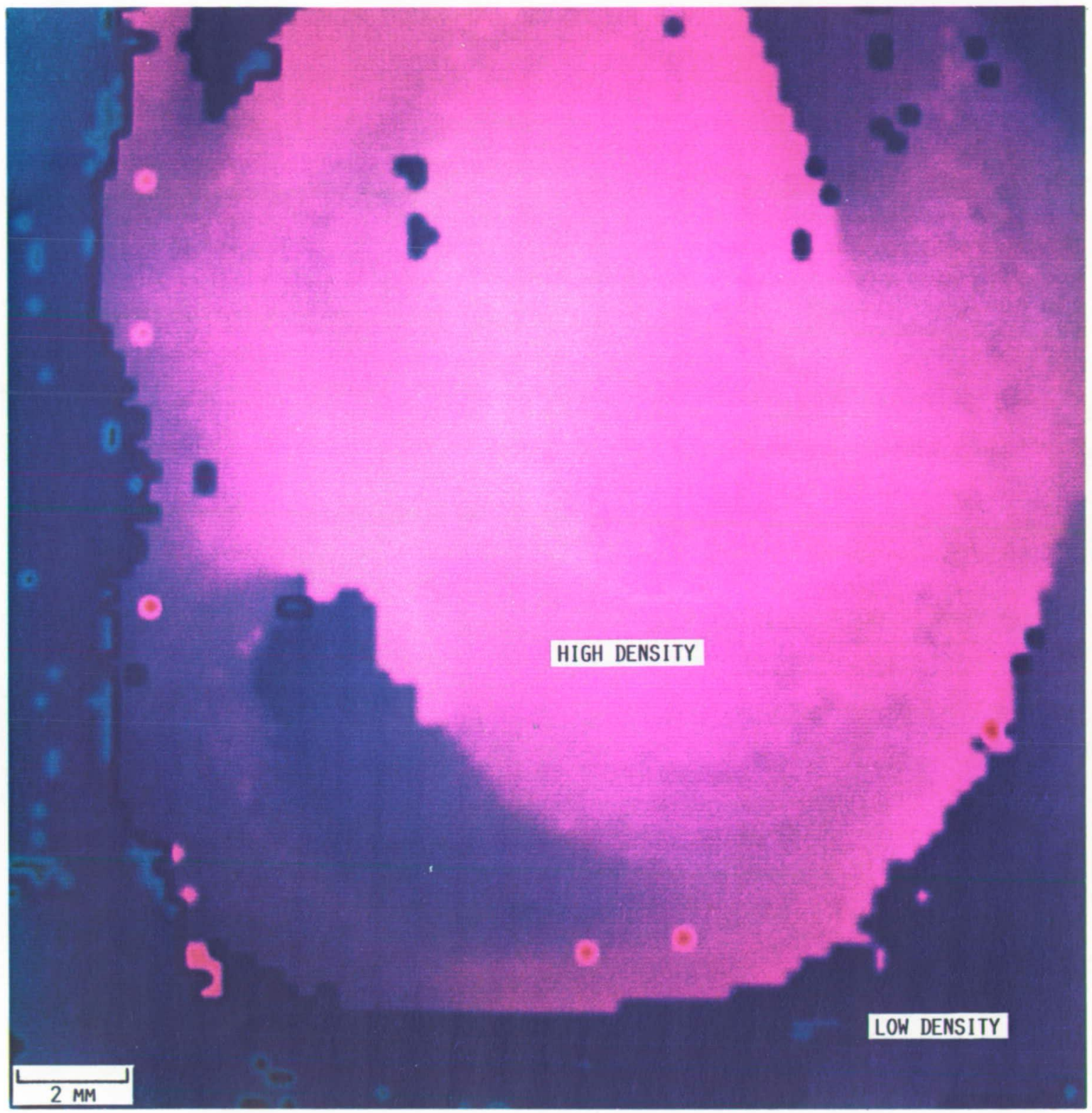

VELOCITY,

CM/ $/ \mathrm{SEC}$

$-1.14$

$-1.09$

$-1.04$

Fig. 16 -- Pass-produced ultrasonic velocity image of SiC. Video image reveals a pear-shaped pattern in porosity structure. There is a sharp boundary between high and low density regions. Area shown is $2 \mathrm{~cm} \times 2 \mathrm{~cm}$. 


\section{ORIGINAL PAGE \\ COLOR PHOTOGRAPH}

ATTENUATION,

$\mathrm{Np} / \mathrm{CM}$

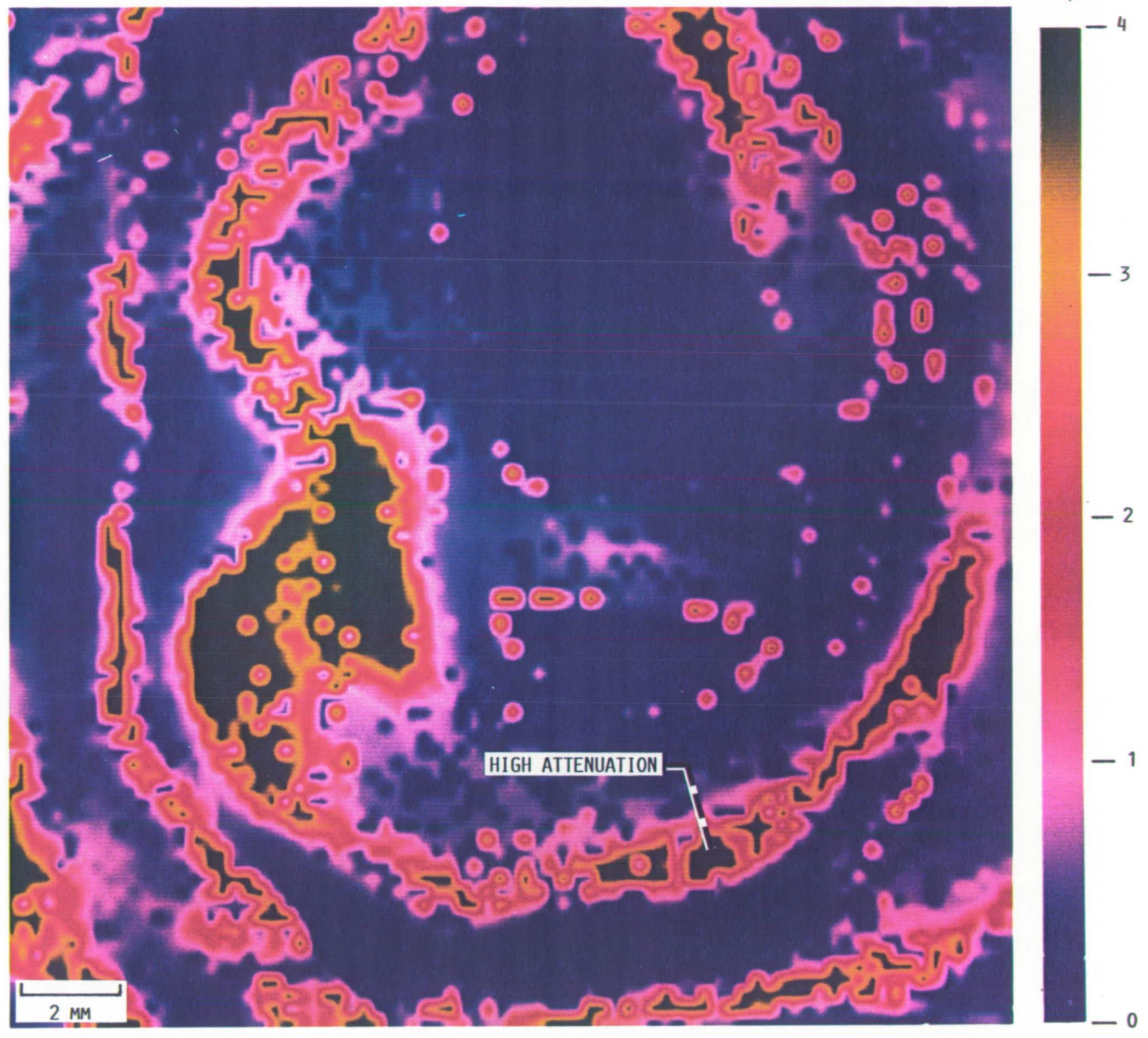

Fig. 17 -- PASS-produced ultrasonic attenuation image of sample region in Fig. 16. Video image reveals high attenuation at sharp high-to-low density boundaries. Area shown is

$2 \mathrm{~cm} \times 2 \mathrm{~cm}$.

SUMMARY

In summary, advances in the nondestructive evaluation of materials microstructure have been made possible by incorporating video systems into the material evaluation process. A video image processing technique for computerized determination of pore and grain size distributions has been described. The impact of the use of video systems on the display, evaluation, and interpretation of ultrasonic data for advanced ceramics has been highlighted. 


\section{REFERENCES}

[1] HITEMP Review 1989: Advanced High Temperature Engine Materials Technology Program, NASA CP-10039, National Aeronautics and Space Administration, Washington, D.C., 1989.

[2] Structural Ceramics, NASA CP-2427, National Aeronautics and Space Administration, Washington, D.C., 1986.

[3] Greil, P., Petzow, G., and Tanaka, H., Ceramics International, Vol. 13, No. 1, 1987, pp. 19-25.

[4] Nickel, K.G., Hoffmann, M.J., Greil, P., and Petzow, G., Advanced Ceramic Materials, Vol. 3, No. 6, Nov. 1988, pp. 557-562.

[5] Freedmann, M.R., Kiser, J.D., and Sanders, W.A., "A Sintering Model for $\mathrm{SiC}_{\mathrm{W}} / \mathrm{Si}_{3} \mathrm{~N}_{4}$ Composites," NASA TM-101336, National Aeronautics and Space Administration, Washington, D.C., 1988.

[6] Wei, G.C. and Becher, P.F., American Ceramic Society Bulletin, Vol. 64, No. 2, Feb. 1985, pp. 298-304.

[7] Kobayashi, S., Kandori, T. and Wada, S., Journal of the Ceramic Society of Japan (Yogyo Kyokaishi), Vol. 94, No. 8, 1986, pp. 903-905.

[8] Ishigaki, H., Nagata, R., Iwasa, M., Tamari, N., and Kondo, I., Journal of Tribology, Vol. 110, No. 3, July 1988, pp. 434-438.

[9] Generazio, E.R., Roth, D.J., and Stang, D.B., Journal of the American Ceramic Society, Communications, Vol. 72, No. 7, July 1989, pp. 1282-1285.

[10] Generazio, E.R., Roth D.J., and Baaklini, G.Y., Materials Evaluation, Vol. 46, No. 10, Sept. 1988, pp. 1338-1343.

[11] Quantitative Microscopy, R.T. DeHoff and F.N. Rhines, eds., McGraw-Hill Book Co., NY, 1968.

[12] Generazio, E.R., Materials Evaluation, Vol. 46, No. 4, March 1988, pp. 528-534.

[13] Generazio, E.R., Materials Evaluation, Vol. 43, No. 8, July 1985, pp. $995-1004$.

[14] Generazio, E.R., Stang, D.B., and Roth, D.J., in The Sixteenth Annual Review of Progress in Quantitative Nondestructive Evaluation, Vol. 9, D.0. Thompson and D.E. Chimenti, Eds., Plenum Press, NY, 1990.

[15] True11, R., Elbaum, C., and Chick, B.B., Ultrasonic Methods in Solid State Physics, Academic Press, NY, 1969.

[16] Generazio, E.R., Materials Evaluation, Vol. 46, No. 9, Aug. 1988, pp. 1198-1203.

[17] Generazio, E.R., Materials Evaluation, Vol. 44, No. 2, Feb. 1986, pp. 198-202, 208. 


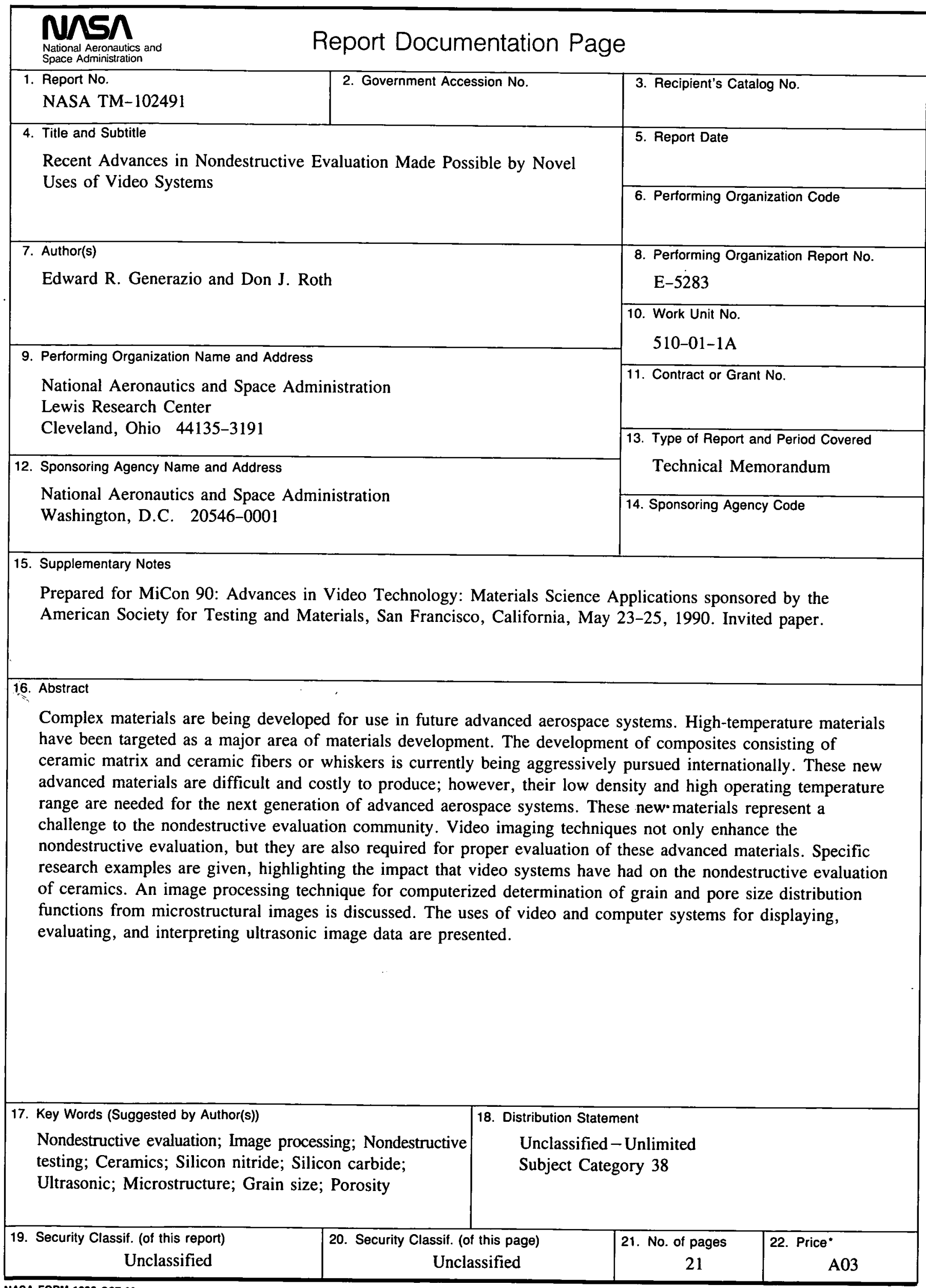


National Aeronautics and Space Administration

FOURTH CLASS MAIL

Lewis Research Center

Cleveland, Ohio 44135

Official Business

Penalty for Private Use $\$ 300$
ADDRESS CORRECTION REQUESTED
|||||

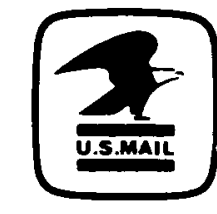

Postage and Fees Pairj

National Aeronautics ano

Space Administratien

NASA 45: 